\title{
As Obras de Arte Aplicada no Direito Brasileiro
}

\author{
Antônio Chaves \\ Catedrático de Direito Civil da Faculdade \\ de Direito da Universidade de São Paulo (*)
}

\begin{abstract}
SUMARIO: 1. As obras de arte apticada, ou desenhos industriais, gozam de dupla proteção - 2. Importancia crescente do "design" - 3. O fato de uma obra de arte ser reproduzida por processos industriais não the retira o carâter artistico - 4. Condiçōes que revelam o carater ilicito da reproducão $\rightarrow$ 5. Duracão da proteção.
\end{abstract}

\section{As obras de arte aplicada, ou desenhos e modelos industriais, gozam de dupla proteção}

As obras de arte aplicada estão expressamente incluídas no âmbito da proteção da Convenção de Berna pelo art. 2, alínea 1, especificando a alínea 7:

"Os países da União reservam-se a faculdade de determinar, nas legislações nacionais, o âmbito de aplicação das leis referentes às obras de arte aplicada e aos desenhos e modelos industriais, assim como as condições de proteção de tais obras, desenhos e modelos, levando em conta as disposições do art. 7.4 da presente Convenção. Para as obras protegidas exclusivamente como desenhos e modelos no países de origem não pode ser reclamada, nos outros países unionistas, senão a proteção especial concedida aos desenhos e modelos nesses países; entretanto, se tal proteção especial não é concedida nesse país, estas obras serão protegidas como obras artísticas".

No âmbito interno protege-as o art. $6^{\circ}$, XI, da Lei brasileira $n^{9}$ 5.988, de 14-12-1973, sob condição, porém, de que "seu valor artístico possa dissociar-se do caráter industrial do objeto a que estiver sobreposto".

\footnotetext{
* "Rapport" apresentado à Comissão de Justiça e Legislação da Confederação Internacional de Autores e Compositores, em sua reunião de Viena aos 10-05-1982.
} 
A terminologia não é muito feliz, mas dá a entender que o objeto de arte aplicada deve ter algum valor artístico para que possa gozar da proteção do direito de autor.

Se passarmos para o âmbito da propriedade industrial, verificaremos que o respectivo Código, Lei $\mathrm{n}^{\circ} 5.772$ de 21-12-1971, abriga apenas as patentes de modelos ou desenhos industriais bem como os modelos de utilidade, invenções e marcas, através de patentes ou modelos de utilidade.

Mas enquanto o direito de autor independe de qualquer formalidade, facultando apenas o art. 17 da Lei $\mathrm{n}^{\circ}$ 5.988: "para segurança de seu direitos", possa o autor da obra intelectual registrá-la, conforme sua natureza, na Biblioteca Nacional, na Escola de Música, na Escola de Belas Artes da Universidade Federal do Rio de Janeiro, no Instituto Nacional do Cinema, ou no Conselho Federal de Engenharia, Arquitetura e Agronomia", e exigindo o art. 53 que a cessão total ou parcial, dos direitos de autor seja sempre feita por escrito, presumindo-a onerosa, devendo para valer perante terceiro, ser averbada à margem daquele registro, o desenho industrial, assim como a invenção e modelo de utilidade, terão assegurado, para garantia da propriedade e uso exclusivo, mediante patente, nas condições estabelecidas pelo art. 5\% do Código de Propridade Industrial, e dando as definições no art. 11:

"1 - modelo industrial toda forma plástica que possa servir de tipo de fabricação de um produto industrial e ainda se caracterize por nova configuração ornamental;

2 - desenho industrial toda disposição ou conjunto novo de linhas ou cores que, com fim industrial ou comercial possa ser aplicado à brnamentação de um produto, por qualquer meio manual, mecânico ou químico, singelo ou combinado, e no

Art. 12 - para os efeitos deste Código, considera-se ainda modelo ou desenho industrial aquele que, mesmo composto de elementos conhecidos, realize combinações originais, dando aos respectivos objetos aspectos geral com caracteristicas próprias".

Acompanhando a opinião mais recente da doutrina, define DAVID RANGEL MEDINA o desenho industrial como "uma disposição de linhas ou de cores que representam imagens que produzem um efeito decorativo original. É um efeito de ornamentação que dá aos objetos um carátes novo e específico.

Em troca, o modelo industrial ou forma plástica, está constituído por uma maqueta, por um modelado, por uma escultura. Desenho e modelo dão aos objetos um caráter novo específico. 
Mas enquanto que o desenho ou arte gráfica opera sobre uma superfície, o modelo ou forma plástica atua no espaço".

"Advertising posters, designed, painted and colored", preleciona STEPHEN P. LADAS, The International Protection of Literary and Artistic Property, Nova Iorque, Macmillan, 1938, vol. I, pág. 224 - "are also artistic works when they embody intellectual creation".

Cita jurisprudência italiana reconhecendo que a adaptação de trabalhos artísticos à publicidade é um fenômeno moderno que aumenta em importância com o desenvolvimento do gosto estético do povo, para concluir:

\section{"Since the intrinsic nature of these works is artistic, their use or purpose is immaterial".}

JOÃO DA GAMA CERQUEIRA, Tratado da Propriedade Industrial, Rio, Forense, 1946, vol. I, observa, a pág. 292, que a lei protege os desenhos e modelos industriais, concedendo aos seus autores um privilégio temporário, que lhes assegura o direito de usar, gozar e dispor de sua obra, bem como o de explorá-la, comercial e industrialmente, de modo exclusivo:

"Assegurando o direito ao uso exclusivo do desenho ou modelo, a lei, em conseqüência, faculta aos titulares do privilégio os meios de tornarem efetivo o seu direito, impondo penas aos contrafatores e a obrigação de ressarcir os prejuizos que causarem".

Acrescenta, pouco adiante:

"Os autores de desenhos e modelos industriais equiparam-se ao inventor, ao escritor, ao artista; e seu direito possui a mesma natureza e fundamento que os demais direitos de autor, sendo uma propriedade fundada no direito natural".

Lembra que, já entre os povos da antigüidade, as artes decorativas ou de ornamentação se manifestavam em forma caracteristicamente artística e na criação de objetos destituídos de utilidade material e acentua que "até os tempos modernos, porém, não se pode com bons fundamentos, discriminar a arte industrial da arte propriamente dita".

A proteção aos modelos e desenhos industriais, ao contrário de significar uma diminuição, procura uma proteção mais eficaz do que gozariam os autores à sombra da lei sobre a propriedade artística.

Justifica tal proteção especial, pois "assimilar às obras de arte pura todos os desenhos e modelos industriais, porque, de raro em raro, surgem entre eles alguns que se podem considerar realmente artísticos e aos quais ninguém recusaria a proteção legal, como obra de arte", 
não lhe parece razoável solução do problema, pois muito maior é o número dos casos em que os desenhos e modelos são destituídos do cunho das verdadeiras obras de arte, a que seriam assimilados sem razão plausível.

"Sob o ponto de vista da proteção dos direitos do autor, nenhum prejuizo resulta da distinção entre as obras de arte $e$ os desenhos e modelos, para submetê-los a regimes diferentes, pois nos casos excepcionais a que nos referimos o autor terá sempre ou a proteção das leis sobre a propriedade artística, ou a das leis sobre os desenhos e modelos industriais, de acordo com os interesses que tiver em vista resguardar e proteger, ou, ainda em certos casos, a dupla proteção dessas leis.

o importante é que o artista, como o industrial, saibam com que proteção poderão contar para a defesa de seus direitos e interesses".

" $A$ reprodução de uma obra de arte por processios industriais ou a sua aplicação d̀ indústria não a desnaturam, não the tiram o caráter artístico".

HERMANO DUVAL, Violação dos Direitos Autorais, Borsoi, Rio, 1968, consigna a págs. 208-209 não importar o meio de reprodução: - "do desenho à figura e desta ao objeto que a materializa não há senão um passo que a lei veda transpor sem o consentimento do desenhista (art. 656 do Código Civil); procede, portanto, a repressão da transformação de figuras conhecidas e protegidas (Branca de Neve e os Sete Anões, Marinheiro Popeye, Betty Boop, Camundongo Mickey, Pato Donald etc.) em cartões, brinquedos, estatuetas, bombons e chocolates".

\section{Importância crescente do "design"}

$\mathrm{Na}$ luta cada vez mais acirrada não apenas pela conquista do mercado interno entre as empresas industriais, como, principalmente, no âmbito internacional, isto é, no setor da exportação para a conquista e a manutenção dos centros de comércio do mundo inteiro, além da qualidade, avulta a importância da aparência.

Desde automóveis, bombas de gasolina, postes de iluminação e Juminárias em geral, até artigos de toalete, eletrodomésticos, aparelhos de jantar e de cozinha, a aparência agradável é a melhor recomendação para a venda.

À medida que a indústria foi se valendo dos designers, percebeu que a contribuição dos mesmos ia muito além de simplesmente melhorar a forma externa de um produto: linhas singelas não só o mantém atualizado, como facilitam e racionalizam sua produção, eliminando 
desperdícios, facilitando a embalagem e o transporte, conquistando espaços no armazenamento.

Em matéria de exportação é muito desigual a luta que sofremos com países que zelam da aparência, como o Japão, a Itália, a Dinamarca.

Nossos produtos não são "brasileiros", isto é, originais, dotados de características próprias, diferentes dos produtos elaborados em qualquer outra parte do mundo.

"Fabricamos geladeiras, automóveis, telefones, equipamentos domésticos, tecidos, roupas, sapatos."

No entanto, "- teve oportunidade aduzir ALOISIO MAGALHÃES -" nenhum desses produtos poderia ser considerado brasileiro, apenas são produtos fabricados no Brasil; se não são simplesmente copiados, pelo menos pertencem ao "mesmo tipo de comportamento: mimetizados do chamado estilo internacional".

Percorrendo as prateleiras dos nossos supermercados nada encontram os visitantes alienígenas que possam adquirir como criação característica da região ou mesmo do país.

\section{O fato de uma obra de arte ser reproduzida por processos industriais não lhe tira o caráter artístico}

Em "Os arquitetos" e proteção do "design", RT Informa, $2^{\text {a }}$ quinzena de junho de 1975, págs. 24-28, encarece NEWTON SILVEIRA que o que qualifica os desenhos e modelos industriais é o caráter supérfluo de seu efeito artístico, que é primordial na obra de arte, na consonância da boa doutrina e do que dispõe a lei sobre direitos autorais, quando considera obra intelectual protegida aquela em que possa dissociar-se o seu valor artístico do caráter industrial do objeto.

A posição dos que alegam que a obra artística não encontra proteção no campo da indústria interpreta incorretamente a legislação estrangeira, que estabelece exatamente o contrário, como o decreto italiano de 1940 que em seu art. $5^{\circ}$ determina a proteção aos modelos e desenhos industriais dispondo que a estes não se aplicam as disposições sobre direito de autor.

"Evidentemente porque quando se tratar de obra artística se aplicarão as disposições sobre direito de autor, como estabelece a lei italiana de 1925, que em seu art. $1^{\circ}$ relaciona como obras protegidas "as obras de arte aplicadas à indústria”. O mesmo ocorre na Espanha, onde o decreto real de 1929, esclarece que se concede a proteção aos modelos e desenhos independentemente dos direitos que possam corresponder-lhes no conceito de propriedade intelectual". 
Demonstra ser, no mesmo sentido, nosso direito positivo: quando se tratar de modelo ou desenho industrial, simplesmente, a proteção é a do Código da Propriedade Industrial; quando se tratar de obra artística a proteção é de direito de autor e abrange qualquer aproveitamento da obra não autorizado como dispõem os arts. 29 e $30 \mathrm{da}$ Lei $\mathrm{n}^{0} 5.988$.

Entre outras hipóteses, não admite como privilegiáveis o art. 13 da Lei $n^{\circ} 5.772$ "as obras de escultura, arquitetura, pintura, gravura, esmalte, bordados, fotografias e quaisquer outros modelos ou desenhos de caráter puramente artístico".

Chega-se, assim, à conclusão de serem as obras de arte aplicada em geral, incluindo as histórias em quadrinhos, em princípio, tuteladas pela Lei $\mathrm{n}^{\circ}$ 5.988, sem prejuízo de que, nas suas adaptações comerciais ou industriais, possam agasalhar-se também sob a proteção do Código de Propriedade Industrial, obedecidas as suas exigências.

$\mathrm{Na}$ verdade, a situação é semelhante à de um quadro, de uma obra de escultura ou de cerâmica, protegidas pela assinatura; forma, modelos, cores, linhas, estilo, padrões, não podem ser copiados ou imitados servilmente para fins econômicos, sob pena de violação do direito de autor: mais do que plágio, verdadeira contrafação, sujeitando os transgressores a todas as conseqüências previstas nas leis penal e civil.

EDMUNDO PIZARRO DAVILA, Los Bienes y Derechos Intelectuales, Lima, Editorial Arica, sem data, tomo I, pág. 90, sustenta a preeminência dos direitos de autor sobre os direitos industriais, demonstrando que o fabuloso progresso da ciência e da indústria originaram a aplicação e multiplicação de objetos e utensílios que, ao lado de sua finalidade prática e utilitária, têm a qualidade e beleza da criação artística, concluindo:

"Frente a la tendencia legislativa universal de separar lo bello y lo ornamental, la ley peruana que protege los trabajos plasticos relativos a cualquier ciencia o arte, y corresponde al magistrado buscar encada caso concreto la diferenciación basada fundamentalmente en los caracteres proprios de la creacion artística, o apoyado en los informes técnicos que solicite".

\section{Condições que revelam o caráter ilícito da reprodução}

Nossa jurisprudência registra, a propósito, casos ilustrativos.

Estabelecimentos de Moda Canadá S.A., do Rio de Janeiro estariam expondo à venda modelos de Linha $\mathrm{Y}$ adquiridos de Christian Dior, o qual, por sua vez, ao criá-los, teria usurpado obra original de Marius Lauritzen Bern, que alega ser de sua autoria idêntica criação. 
In abstracto, tratar-se-ia do crime de contribuição ao êxito de contrafação, a que se refere o parágrafo único do art. 184 do Código Penal, visto como também constitui crime contra a propriedade intelectual vender ou expor à venda, adquirir ocultar ou ter em depósito, para o fimi de venda, obra literária, científica ou artística, produzida com violação do direito autoral.

Nessa hipótese, na lição de NELSON HUNGRIA, Comentários ao Código Penal, Rio, Ed. Rev. Forense, 1955, vol. VII, no 114, pág. 335, "deve entender-se que o agente não participou da' impressão, composição ou fatura da obra fraudulenta (seja no país, seja no estrangeiro), mas vem, ciente da fraude, a prestar auxílio à sua difusão, vendendo- $a$ ou expondo- $\alpha$ a venda, adquirindo- $\alpha$, ocultando- $\alpha$ ou recebendo- $a$ em depósito para o fim de venda. Não se trata de uma hipótese de receptação especialmente incriminada, mas de concurso à execução do crime (que não é apenas a fraude na impressão, composição ou fatura da obra, senão, também, necessariamente, a sua subseqüente divulgação), entendendo a lei de configurar na espécie um crime autônomo (como modalidade de contrafação). Não importa que o agente (vendedor, expositor à venda, adquirente, ocultador ou depositário) proceda lucri faciendi causa para prestar um favor ao anterior contrafator".

A matéria foi decidida pela Quinta Câmara Civil do Tribunal de Justiça do Distrito Federal, em acórdão unânime de 05-08-1958, Diário da Justiça de 19-02-1959, págs. 578 e 579, apelação civil n 45.213:

"Direito Autoral. Artigos de Moda. O direito autoral não protege as criações de linha estéticas para vestuário feminino destinado a determinada estação por isso que tombam desde logo no dominio público, e, em conseqüência, o seu aproveitamento ou adequação por terceiros não constitui ato de contrafação.

Plágio. O aproveitamento de uma linha original de vestuário na confecção de modelos, constituindo a utilização de um trabalho de arte figurativa preexistente para obtenção de obra nova, posto que possa representar um plágio de concepção, nãa é considerado ofensa ao direito do autor".

Trevoli S.A. - Artefato de Couro e Plásticos utilizou em pastas escolares e embalagens para presentes, figuras de autoria de Elizabeth Barbosa Duarte.

Acórdão do Tribunal de Justiça do Rio de Janeiro de 15-07-1975, RT 505/230 reconheceu:

"Caracterizada a ofensa ao direito autoral, pelo aproveitamento e exploração industrial de criação artística alheia, 
sem autorização do autor da obra é, cabivel a indenização prevista no art. $672 \mathrm{CC}$, não se aplicando ao caso, entretanto, o tipo de reparação a que se refere o art. 669 do mesmo Código".

Submetem, pois, nossos tribunais a arte aplicada à proteção do direito de autor.

EDUARDO PIOLA CASELLI, ALFREDO ARIENZO e FRANCO BILE, Diritto d'Autore, Novíssimo Digesto Italiano, demonstram não ser lícito levar a utilização de obra alheia até ao ponto de usurpar o conjunto dos próprios elementos, do qual irradia a individualidade da representação pessoal alheia.

"Quando isto acontece, e quando pois, seja possivel reconhecer na nova obra, apesar das variantes, acréscimos ou reduções, a individualidade de representação de uma obra preexistente, deve-se concluir que a obra nova é contrafação da antiga".

Para certificar a existência de uma contrafação é suficiente verificar se entre duas obras existe uma "identidade de representação" que possa ser reconhecida, isto é, se as duas obras ostentam duas visões diferentes e originais, ou se, ao invés, têm um aspecto substancialmente único.

É claro que nem toda reprodução constitui necessariamente uma contrafação.

Para que isso ocorra é necessário, ensina J. LABAURIE, L'Usurpation en Matière Litteraire et Artistique, Paris, Boccard, 1979, pág. 48, a concurso de três elementos:

$\left.1^{\circ}\right)$ que tenha sido feita sem autorização;

$\left.2^{2}\right)$ que a obra reproduzida não tenha ainda caído no domínio público;

$3^{\circ}$ ) que constitua uma edição, conceito esse que o desenvolvimento da tecnologia fez desprender-se da relação com a edição de livros, para abranger, hoje em dia, toda e qualquer multiplicação de exemplares.

São pois três as condições pelas quais revela a reprodução seu caráter ilícito:

a) uma obra ainda protegida;

b) a falta de autorização;

c) a publicação, conceito que adaptado à nossa lei redundará na reprodução para fins de comércio. 
"Quem imprimir obra literária, artística ou científica, sem autorização do autor", - estatuem os arts. 122, 123 e 124 da Lei $n^{\circ} 5.988$ de 14-12-1973 - "perderá para este os exemplares que se apreenderem, e pagar-lhe-á o restante da edição ao preço por que foi vendido, ou for avaliado.

Não se conhecendo o número de exemplares que constituem a edição fraudulenta, pagará o transgressor o valor de dois mil exemplares, além dos apreendidos.

O autor, cuja obra seja fraudulenta, reproduzida, divulgada ou de qualquer forma utilizada, poderá, tanto que o saiba, requerer $a$ apreensẫo dos exemplares reproduzidos ou a suspensão da divulgação ou utilização da obra, sem prejuízo do direito à indenização de perdas e danos.

Quem vender, ou expuser à venda, obra reproduzida com fraude, será solidariamente responsável com o contrafator, nos termos dos artigos precedentes; e, se a reprodução tiver sido feita no estrangeiro, responderão, como contrafatores, o importador e o distribuidor".

Se fosse possível percorrer não duas, mas centenas de lojas, todas as lojas existentes na cidade, no Estado, no País, encontrar-se-iam, há alguns meses atrás, dezenas de milhares de confecções ostentando inúmeras etiquetas falsificadas.

O abuso chegou a tal ponto que colocava o própria País em situação profundamente desairosa, como ressaltava, no dia 10-01-1981, uma correspondência do GILLES LAPOUGE, de Paris, para o Jornal da Tarde, denunciando a "pequena guerra econômica" que se insinuava entre o Brasil e a França a poucos dias da viagem do presidente Figueiredo.

Explica que algumas firmas francesas de renome internacional: Christofle, Hermes, Paco Rabanne, Lacoste, tentavam despertar a atenção para os verdadeiros "atos de pirataria", por parte de certas indústrias brasileiras, que seriam "estimulados pela complacência das autoridades brasileiras"

$\mathrm{Na}$ verdade, até há pouco tempo as providências legais que podiam ser tomadas pelas vítimas desse verdadeiro e descarado assalto eram tão precárias e demoradas que levavam os titulares de direitos e descalabros econômicos e ao desespero psicológico diante da impotência de impedí-lo.

Mas a situação veio a modificar-se completamente em virtude da alteração profunda introduzida nos arts. 184 e 186 do Código Penal pela Lei $n^{\circ}$ 6.895, de 17-12-1980, a deixar bem claro que os casos descritos individualizam não mais apenas um mero ilícito civil, mas verdadeiro crime. 


\section{Duração da proteção}

Nos termos do art. 7, alínea 4 da Convenção de Berna, "os países da União reservam-se, nas suas legislações nacionais, a faculdade de regular a duração da proteção das obras fotográficas e das obras de arte aplicada protegidas como obras artísticas; entretanto, a referida duração não poderá ser inferior a um período de vinte e cinco anos contados da realização da referida obra".

Dilata, no entanto, excessivamente esse prazo a Lei $\mathrm{n}^{\circ} 5.988$, para 60 anos a contar de $1^{\circ}$ de janeiro do ano subseqüente ao de sua conclusão, quando na verdade tais objetos tornam-se obsoletos no curso de cinco, ou, no máximo, de 10 anos.

Já no âmbito da propriedade industrial, o prazo de proteção exclusiva das patentes é de 15 anos para as invenções e de 10 para os modelos de utilidade e modelos ou desenhos industriais contados do depósito.

\section{Bibliografia Aproveitada}

ARE, Mario - L'Oggetto del Diritto di Autore, Milão, Giuffrè, 1963, págs. 412-455.

MEDINA, David Rangel - Protección al Arte Aplicado. RIDI, Rev. Interamericana de Direito Intelectual, vol. 1, ne 1, 1978, págs. 63-68.

PEROT-MORELL, Marie-Angèle - La Protection Internationale des Arts Appliqués a l'Industrie dans le Double Cadre des Conventions Relatives a la Propriété Industrielle et au Droit d'Auteur, Il Diritto di Autore, Volume Celebrativo del Cinquantenario della Rivista, Studi in Omaggio a VALERIO DE SANCTTS, Giufrè, Varese, 1979, págs. 553-567.

SERVIN, José Luís Rincon - El diseño industrial patenttable, Rev. Mexicana de la Propriedad Intelectual y Artística, nos 27-28, 1976, págs. 225-236.

SILVEIRA, Newton - Proteção ao "Design", RIDI, Rev. Interamericana de Direito Intelectual, vol. 1, no 1, 1978, págs. 69-74. 